\title{
A Cognitive Analysis of Woman Metaphors in Ekegusii Language
}

\author{
Aunga Solomon Onchoke ${ }^{1, *}$, Xu Wen ${ }^{2,3}$ \\ ${ }^{1}$ Department of English and Linguistics, Southwest University, China \\ ${ }^{2}$ Dean College of International Studies, Southwest University, China \\ ${ }^{3}$ Department of English and Linguistics, College of International Studies, China
}

Copyright $\mathrm{O} 2017$ by authors, all rights reserved. Authors agree that this article remains permanently open access under the terms of the Creative Commons Attribution License 4.0 International License

\begin{abstract}
It has been argued by linguists that language expresses a people's way of life; this paper examines a cultural-specific metaphor in Ekegusii, an African Bantu language in Kenya since a metaphor makes our thoughts clearer, richer with imagery, and, act as a conduit between human mind and culture. A qualitative research design was used in the collection of the metaphors from the two counties of Gusii, Nyamira and Kisii, where 60 native respondents were picked and asked to identify and explain terms and phrases that describe a woman in Ekegusii, describe the social-cultural values and explain the mapping processes involved. The data was analyzed by identifying qualities in the donor domains and mapping them to the recipient domain using the Cognitive Metaphor Theory (CMT). It is clear from the results that in Ekegusii, a woman is perceived as an object, a plant, an animal or the appropriate behavior she exhibits based on the values such as immorality, selfishness, beauty, ugliness, harshness, talkativeness, age, and faithfulness, and also, the cultural background plays an important role in the conceptualization and interpretation of these metaphors. Finally, we recommend more research of metaphors in other languages to enable comparisons.
\end{abstract}

Keywords Metaphor, Cognitive Linguistics, Culture, Woman, Ekegusii

\section{Introduction}

This is a paper on how the Abagusii community in Kenya perceive a woman in view of the Conceptual Metaphor Theory (CMT) which is a major concern to cognitive linguists as they research on how language reflects people's perception of the world. According to Guthrie (1964), Ekegusii, whose speakers are called Abagusii, living in Gusii land, is labeled zone E42 narrow East African Bantu language group in Kenya. The language has two dialects; rogoro and maate, but we used the rogoro dialect which has more speakers and considered to be more prestigious (Bosire, 1993). The Abagusii, just like other communities, are rich in culture. From their history, there was a clear division of work between males and females. Being a patriarchal and patrilineal $^{1}$ society, women were culturally segregated, and married off from their clans, and therefore, had no say in their marriages (Thomas, 1994). Many cognitive linguists have explored the subject of women and how they are perceived in different cultures. Among them is Kovecses (2008) who posited that the way men and women talk about each other generally, differ. Additionally, in most other societies, women are treated as lesser human beings by use of different metaphors and slangs as compared to men. Women are conceptualized as sweet food, objects, commodities, desserts, substances, animals, birds and children (Lakoff, 1975; Kovecses, 2006, 2010; Hines, 1994 \& Phenelope, 1977). It is a fact that some of the metaphors are culture specific and others universal (Kovecses, 2005). Gleason (1961) postulates that language and culture are closely related and that language is part of culture, consequently, it is used to maintain and convey culture and cultural ties. In this study, we present the Ekegusii social-cultural woman metaphors illustrating how they are formed and interpreted. This will add to the few Ekegusii cognitive linguistics works like that of Nyakoe et al. (2012). First, the previous research based on the Cognitive Metaphor Theory is discussed, followed by the methodology on how the metaphors were collected. The main part analyzes the data to illustrate various characteristics of Ekegusii woman metaphors and finally, we present the conclusion.

\section{Theoretical Framework}

Lakoff and Johnson (1980) is accredited with the

1 Patrilineal it is inheritance of property, children and wives passed from father to son. Patriarchal is a system where the males are the heads of families 
Cognitive Metaphor Theory (CMT), and later expounded by researchers within the field of cognitive linguists. They acknowledge the existence of the metaphor as pervasive in everyday life, a tool for understanding, and that, it is a property of cognition. They argued further that in CMT, imagination to map and understand experiences metaphorically or metonymically on the basis of image schema with ${ }^{2}$ ontological correspondences between the domains ( source or $\mathrm{X}$ and target or $\mathrm{Y}$, where the latter is understood in terms of the former); at the level of language, entities, attributes and processes in the target domain are lexicalized using words and expressions from the source domain (Croft and Cruse, 2004; Lakoff and Johnson,1980,1991,1993，1999 \& 2003; Kövecses, 2002 \&2005; Gibbs, 1994; Langacker, 1999; Grady, 1997; Evans and Green, 2006). Therefore, they view a metaphor as understanding one conceptual domain in terms of another (Ritchie, 2013). ${ }^{3} \mathrm{Jakel},(2002: 20-42)$ has summarized the basic tenets of the Cognitive Theory of Metaphor in the form of nine hypotheses as postulated by different cognitive linguists as ubiquity, domain, model, diachrony, unidirectionality, invariance, necessity, creativity and focusing. The nine will be applicable in this study in giving focus.

In cognitive linguistics, many scholars argue that the metaphor is important in understanding the relationship shared by language, thought, and culture (Gibbs, 1994). Another scholar, Kevesces (2005), had questioned the universality of metaphors as early on suggested by Lakoff, he noted that the cultural context is important in interpreting metaphors and that majority of metaphors are culture specific. Ritchie (2013), in his book, Metaphor; identified and described the different types of metaphors and asserted that many primary metaphorical concepts are based on culture-specific experiences. This position had also been adopted by Lyons (1968:432), who contended that the language of a people is an important component of its culture and that vocabulary chosen by languages show culturally

2 Ontological correspondences are the processes by which the source entities (people, objects, plants, actions or states are mapped onto their counterparts in the target domain.

3 Jakel (2002: 20-42) summarizes the basic tenets of the Cognitive Theory of Metaphor in the form of nine hypotheses as postulated by different cognitive linguists as follows: ubiquity hypothesis where linguistic metaphor is seen as perfectly ordinary everyday language; domain hypothesis where metaphorical expressions are not to be treated in isolation, but as linguistic realizations of conceptual metaphors with source and target domains; model hypothesis where conceptual metaphors form coherent cognitive models(ICMs); diachrony hypothesis where cognitive-semantic studies of metaphor can benefit from the integration of the diachronic dimension; unidirectionality hypothesis where in metaphor (" $\mathrm{X}$ is $\mathrm{Y}$ ") links an abstract and complex target domain (X) as explanandum with a more concrete source domain (Y) as explanans, which is more simply structured and open to sensual experience; invariance hypothesis is where in conceptual metaphors, certain schematic elements get mapped from the source domain onto the target domain without changing their basic structure; necessity hypothesis stresses that metaphors have an explanatory function; creativity hypothesis proposes that the potential meaningfulness of metaphor does not yield to simple paraphrase; its meaning cannot be reduced to a non-metaphorical, propositional format without loss and focusing hypothesis that emphasizes that metaphors only supply a partial description or explanation of the target domain in question, highlighting certain aspects while hiding others. important features of their philosophy, objects, institutions, and activities in which the language operates. Consequently, many other researchers have stressed the importance of culture in conceptual metaphor studies like Maalej (2004) and Azuma (2012) who concluded that the differences in culture affect the interpretations of the metaphor. This study will benefit from their methodologies because they are based on African Languages, just like Ekegusii.

Early cognitive linguistics had identified ${ }^{4}$ structural and orientational metaphors (Lakoff and Johnson 1980). Other linguists, later, like Grady (1997), discussed further the different types of metaphors and expounded on the CMT by identifying and distinguishing between ${ }^{5}$ complex and primary metaphors, and introduced a "resemblance hypothesis". According to his model, he posited that there are image metaphors, called 'social-cultural metaphors' because the two domains are associated social- culturally associated. Using this metaphor, Takada, et al., (2006), carried out a research on how a Japanese woman is conceptualized. This paper will elaborate on the social-cultural metaphor model as resented by Grady, (1997) \& Takada, et al. (2006) in Ekegusii, an African minority Bantu language in Kenya.

\section{Methodology}

The paper adopted a qualitative research design. It sought to describe a phenomenon that occurs naturally without the intervention of an experiment or artificially contrived treatment (Seligar and Shohamy, 1989). This is a synchronic study, carried between July and December, 2016, it describes the phenomenon as it exists at a particular point in time. The study population entailed Ekegusii informants from Nyamira and Kisii counties of the Abagusii native speakers comprising adults of between 50 and 70 years of age, born and brought up in Kisii. They were chosen from the many using judgmental sampling techniques. Taking into account the variable of gender to avoid bias, the informants included 30 men and 30 women. This small sample was chosen in order to allow for in-depth investigation and analysis of data (Trudgill, 1973). The study utilized an interview schedule where the respondents were subjected to the same questions and grouped according to the variable of gender. The interview schedule had open-ended questions which permitted a greater depth of response which in turn gave an

4 Structural metaphors provide a means of structuring one concept in terms of another. Orientational metaphors, on the other hand, are cases in which a metaphorical concept organizes a whole system of concepts with respect to one another, especially in terms of understanding experience in terms of objects, actions as substances, and states as containers ( Lakoff and Johnson 1980:80)

5 Primary metaphors are motivated by bodily experience like MORE IS UP. On the other hand, a complex metaphor is a metaphor (or figurative comparison) in which the literal meaning is expressed through more than one figurative term or a combination of primary metaphors. Also known as a compound metaphor e.g. HUNGER IS FLUID IN A HOT CONTAINER (Grady, 1999, Kovecses 2002 and Lakoff, 1999) 
insight into the feelings, background, hidden motivation, intuitions, interests and decisions of the respondents (Mugenda and Mugenda, 1999).

The researcher asked the respondents to name terms and phrases used to describe women and what the words meant. In addition, the researcher asked them to describe the different meanings associated with the words and phrases. They were further asked to name the contexts in which these alternative terms were used and the reasons for their usage. This study, therefore, utilized primary data in order to obtain detailed information about how women are described and then proceeded to establish patterns and relationships from the gathered information. The interview schedule was augmented by tape-recording which increased the level of accuracy without interfering with the process (Mugenda and Mugenda, 1999).

The data obtained was presented in Ekegusii orthography and a translation to the nearest gloss in English provided. The recorded data was transcribed first and thereafter translated. Field notes written during the sessions were used to supplement the recorded data especially in cases where references to particular items were unclear. The transcribed data was edited in order to come up with a clean and organized copy to facilitate recall of information. This was thereafter followed by translation of the copies from Ekegusii to English. The words and phrases that were collected were sorted out and classified into different categories by looking at the values that were related. A list of these categories was then compiled and patterns emerged. In addition, the mental imagery that the words and phrases showed were explained and the researcher proceeded to show how these words and phrases were viewed in the Ekegusii society. The social cultural values from the data on the interpretation processes were then mapped from the source domain to the target domain and analyzed using the Cognitive Metaphor Theory.

\section{Results and Discussion}

In this section, we will examine metaphors in Ekegusii that conceptualize the woman as animals, plants, objects or a name corresponding with the character exhibited using the social-cultural metaphor model, and discuss how well it can explain the mapping process involved.

The data that was collected from 60 competent Ekegusii native respondents comprised 60 words describing how a woman is conceptualized. Based on the CMT, the words were transcribed and translated into gloss English. A clear pattern was sort and then the metaphors were classified first to either positive or negative character traits, then later, into objects, plants, animals or character exhibited as source domains. Tables and pie charts were used to aid the presentation of the responses obtained. The figure that follows gives a summary of words describing a woman in Ekegusii as collected from the respondents.

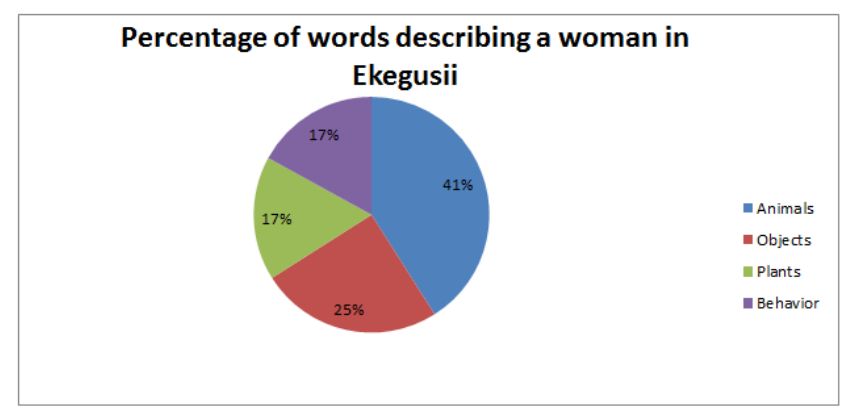

Figure 1. Summary of woman metaphor in Ekegusii

Figure 1. Represents in percentages the 60 words collected from the respondents describing a woman in Ekegusii as illustrated in table I below. Based on the CMT, the words were classified to animals, plants, objects or behavior exhibited by the woman. There were 25 names for animals, 15 for objects, 10 for plants and behavior, representing $41 \%$, $25 \%$, and $17 \%$ for the last two, respectively. (A full list of the words and meanings, see the appendix)

Table 1. Summary of the broad areas mapped and the domains

\begin{tabular}{|c|c|c|c|c|c|}
\hline Traits mapped & Animals & Objects & Plants & Behavior & Total \\
\hline Positive & 3 & 5 & 4 & 3 & 15 \\
\hline Negative & 22 & 10 & 6 & 7 & 45 \\
\hline & 25 & 15 & 10 & 10 & 60 \\
\hline
\end{tabular}

Table 1, above shows that most of the qualities given to a woman in Gusii land were negative; 45 metaphors representing $75 \%$ of the total represented negative character traits and only 15 representing $25 \%$ of the total represented positive character traits. This, may be, could be explained by the fact that the community is patriarchal and women are treated lowly by men. The perception here is that men are better and more intelligent than women, which is not always the case.

The research used a social- cultural metaphor model (Grady 1999; Takada et al. 2006)) which links a culture's understanding and conceptualization on its social- cultural setting, this means that how Abagusii community understand and conceptualize a woman will depend on the socialcultural setting. For instance, in the Ekegusii metaphor "omokungu ne embeche." a woman is conceptualized as a warthog. In Gusii land, women are supposed to be beautiful in their own social-cultural weighing scales of "beauty". A warthog is an African wild pig with long front teeth that stick out of the side of its mouth. Warthogs are seen as very ugly animals. Here, ugliness, in the Gusii community context, is socially defined for human beings, and the warthog is determined as of the proto-typical category that possesses ugliness. Then, the source concept "ugliness of a warthog" is mapped onto the target concept "ugliness of human being who is a woman." The reason behind this mapping is that the source and target domains share a similar value that is socially defined. This is in line with Kövecses (2005) who said that a metaphor is based on similarity and cross-domain 
correlations in our experiences. This model fits in this study because specific qualities of the source domain (objects, animals, plants or behavior) as understood and perceived in Ekegusii culture, are mapped onto the target domain (a woman).

In addition, it is understood that metaphors convey the images, feelings, customs, values and thought patterns found in our cultures (Mittelberg 2007:34). In mapping within the animals, objects, and plants used for a woman, not all properties are mapped. The metaphor makes sense when only culturally accepted features for the animals, plants, objects or behavior exhibited are picked leaving out irrelevant traits, therefore, it is true that metaphors are selective because they highlight particular aspects of the source and the target while hiding others (Lakoff, 1993\& Jackel, 2002). For instance, in the metaphor, omokungu ne engoko, a woman is a conceptualized as a hen, meaning an immoral woman. The aspect of the hen as a source domain highlighted is the one of being promiscuous (laid anyhow by the cocks) and then it is mapped onto a loose woman (target domain). Other qualities of a hen like its productivity of laying of eggs, provision of sweet meat and stupidity because of its eating habits and leaving its droppings all over are seen as irrelevant, hence, suppressed.

\section{Values Mapped}

According to Lakoff and Johnson (1980), the woman metaphor in Ekegusii could be analyzed as "A WOMAN IS AN ANIMAL, A WOMAN IS AN OBJECT, A WOMAN IS A PLANT or A WOMAN IS HER BEHAVIOR" basic conceptual metaphors. But we realized that this could not capture adequately the values mapped as conceptualized by the community. By analyzing various kinds of animals, plants, objects or behavior exhibited in terms of their properties that are mapped or unmapped, we found a set of positive and negative properties that are crucial in woman metaphors in Ekegusii. The positive and negative traits could also be analyzed based on the conceptual metaphors: POSITIVE IS UP and NEGATIVE IS DOWN or STRENGTH IS UP or BIG IS UP and WEAKNESS IS DOWN or SMALL IS DOWN (Lakoff and Johnson, 1980 \& 1987). This could not have also captured the native speakers' conceptualization about their culture. The metaphors are formed based on physical appearance or feature of an animal, plant, object or behavior exhibited, and some of them are used because of those traits which folk models decide about them (Rouhi, 2011). Here, according to Ekegusii folk tales, for example, the animals, plants or objects are depicted behaving like human beings. In this way, they are shown with family relationships similar to humans. Such family members have duties spelt out. Outside, they have groupings with leaders (kings or rulers) and even soldiers doing their duties. For example, engombe (cow) is a foolish woman despite its big size and the ability to provide milk and beef when slaughtered. Similarly, egesusu (hare) is a tiny animal but a woman given the name is conceptualized as mature and clever. We used a social cultural model where the qualities mapped from the source domain to the target domain are social-culturally understood and interpreted (Grady 1997 and Takada et al., 2006). The following qualities were identified: beauty, ugliness, immorality and selfishness, talkativeness, parasitism and laziness, hypocrisy, fierceness, and age. The qualities acted as the source domain as extracted from the animals, objects, plants or behavior. Graph1 gives a summary of number, percentages and specific qualities mapped from the source domains to the target domain (woman).

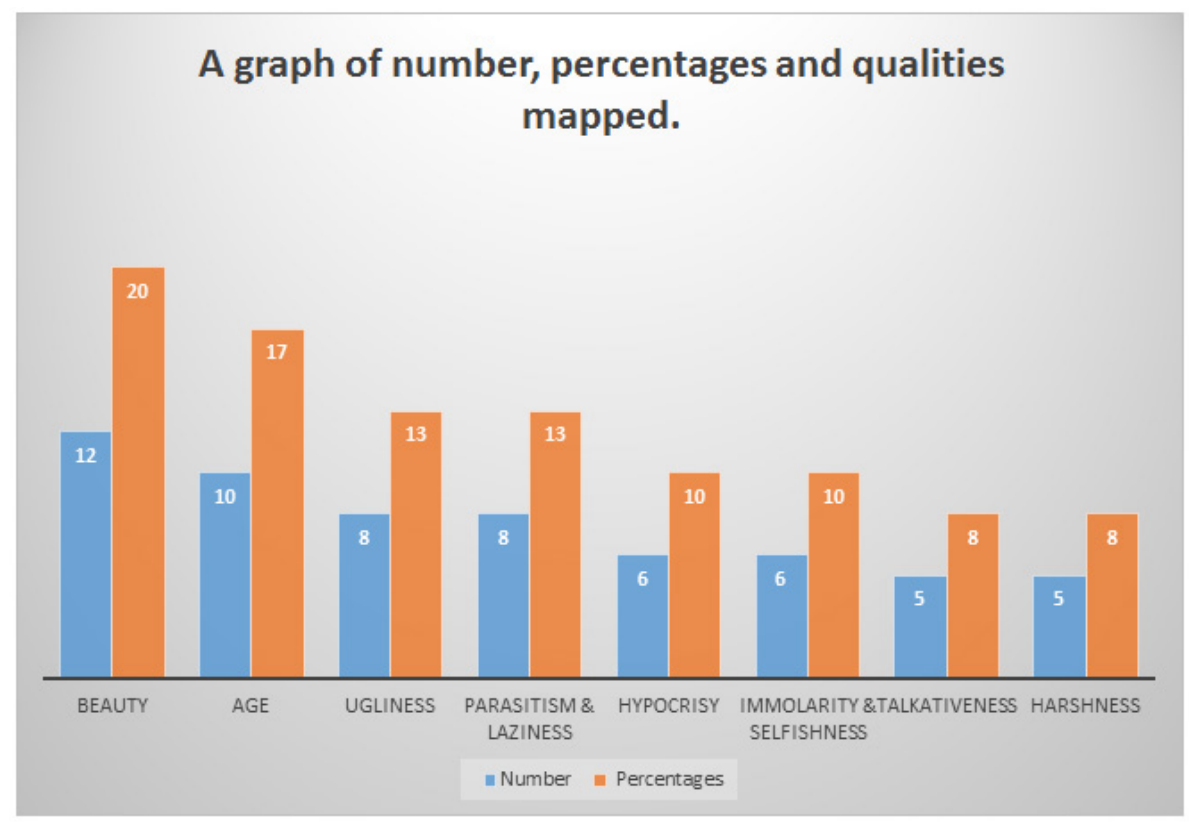


Graph 1 gives a summary of the qualities, number and percentages mapped from the donor to the recipient domains. There were 60 qualities representing $100 \%$. They were compressed to 8 areas to avoid repetition. Beauty was the highest at 12 which is $20 \%$, followed by age at 10 representing $17 \%$; ugliness and parasitism each at 8 which is $13 \%$; hypocrisy and immorality each at 6 representing $10 \%$ and finally, talkativeness and harshness each at 5 which is around $8 \%$ in that descending order.

According to the respondents, the Abagusii view a woman as an adult female human. Ross (2001) describes a woman universally using the semantic primitives: + female, + mature and +- parent. The Abaugusii culture expects a woman to be socialized in a way that is different from the man. Being a patriarchal society, women are treated as inferior hence given names meant to perceive them as the weaker sex. Studies carried out by Okindo (1995) and Choti (1998) depict a woman as being positioned lower than a man in the Gusii society. This may explain the many negative traits a woman was given. In these studies carried out in Ekegusii, they attributed differences in men's and women's social ranks to social forces rather than biological ones. Men and women are different because the society offers different roles for them and expects different character patterns (Trudgill, 1973:88). This also explains the motivations behind the many names of a woman in Ekegusii.

The relative status of the sexes in Abagusii society may be reflected not only in the ways in which women and men use language, but also in the languages used by women and men. Gender, apart from being a biological construct, is an aspect of culture which assigns men and women certain roles that cause variation in lexical choice based on context. It should be noted that the positive qualities are the ideal; negative characteristics are meant to mock a woman who lacks the salient qualities of a good woman, different cultures view these qualities differently. This is in line with the position adopted by Lyons when he contends that:

The language of a particular society is an integral part of its culture, and...the lexical distinctions drawn by each language will tend to reflect the culturally important features of objects, institutions, and activities in the society in which the language operates (1968:432).

We decided to group the traits that are almost the same together for easy analysis, discussion and to avoid repetition. However, it should be noted that not all animals, plants and objects collected from the field were discussed; we only present a few to illustrate the woman metaphor in Ekegusii. It should be noted that, considering the socio-cultural codes in Ekegusii, the majority of woman metaphors seem to be based on the perspective of men. Men seek in women certain properties. The discussion that follows gives a summary of a few of the qualities mapped or unmapped from the source domain to the target domain to illustrate the correspondences.

(A) BEAUTY. Women are perceived as sweet fruits that are edible by men. It was realized that fruits that had the value of sweetness and yellow in color when ripe, were mapped onto beautiful women who are human beings. This is a physical attribute. There is a common saying that beauty is in the eyes of the beholder. Animals perceived as having the quality of beauty were also mapped onto a beautiful woman. It should be noted that not all ripe yellow fruits and beautiful animals were considered beautiful. Lakoff and Johnsons (1980), conceptual metaphor, A WOMAN IS FOOD, could not capture the whole process of the qualities mapped. There is Ekegusii social-cultural codes that assign these qualities to particular fruits and animals. What counts as beautiful or lovable, however, depends on how men evaluate these properties in women. Thus, this is also a kind of "social value" interpreted especially by men because it is a patriarchal society.

\begin{tabular}{cc}
\multicolumn{2}{c}{ Ontological Correspondence } \\
Source Domain & Target Domain \\
Sweetness and yellow color of a ripe fruit $\longrightarrow$ Beauty of a woman \\
Beauty and sweetness of an animal/bird $\longrightarrow$ Beauty of a woman
\end{tabular}

In plants, the respondents called a woman the following fruits: ensobosobo meaning wild fruit; a type of sweet yellow orange wild fruit. Another related name is egesukari, which is a type of sweet banana which is yellow and very sweet when ripe. Enyanya is a tomato; a red or yellow pulpy edible fruit. The qualities mapped here are color and sweetness. Some respondents also argued that the shape is also mapped, especially, the shape of a tomato to a shape of a woman with big butts. A beautiful woman, among the Abagusii, is perceived as yellow or light skinned which is the color for being ripe and 'sweet'. Sweetness here, according to the respondents, is sexual enjoyment as viewed by men. This is also in line with the conceptual metaphors, WOMEN ARE SWEET THINGS or WOMEN ARE FOODS and WOMEN ARE OBJECTS or COMMODITIES (Kovesces (2006). This emphasizes the point that Abagusii are male Chauvinists who view women as sex objects to be enjoyed by them. A woman given any of the three names is seen as beautiful, thus, admired by many men.

The respondents identified entuga, a flying white termite; two winged edible flying termite rich in protein, as a carrier of beauty. The wings give the ant the outside beauty. Beauty and sweetness of this termite are mapped onto a beautiful Gusii woman. This is in line with the conceptual metaphors, WOMEN ARE FOOD or WOMEN ARE OBJECTS OF LUST to be enjoyed by men. The sweetness was linked to sexual enjoyment by men. This ant is perceived as beautiful and sweet by the Abagusii. Nyaigoti chenge is a hen; a domesticated foul whose neck is not covered with feathers. This type of hen, according to Abagusii culture, is considered as very beautiful and sweet when cooked. The bare neck gives the hen outside beauty. The outside beauty as perceived by the Kisii men and sweetness of this hen is mapped onto a beautiful woman. 
When the respondents were asked how they tasted the sweetness of women before having sex, they argued that sex is psychological and that if a woman is beautiful from outside then, she was considered sweet or sexy, a belief held by many men.

B) AGE. A woman behaving badly like being promiscuous, lazy, foolish, hypocrite and liar, was seen as immature. If she behaved well like loving, respectable, hardworking and truthful, she was perceived as elderly, full of wisdom, and mature. A woman attracted a particular name corresponding with the behavior exhibited. This is in line with other cultures in conceptual metaphors by Kovecses (2006), WOMEN ARE CHILDREN or WOMEN ARE OLD WOMEN. A woman conceptualized as a child is inexperienced and immature. On the other hand, a woman perceived as an old woman is seasoned, respectable and mature.

\begin{tabular}{cr}
\multicolumn{2}{c}{ Ontological Correspondence } \\
Source Domain & Target Domain \\
Good/Bad behavior of a woman $\longrightarrow \quad$ Age of a woman
\end{tabular}

A woman behaving badly was given names such as egesagane or omwana, meaning a young, uncircumcised girl or a child, respectively According to Abagusii culture, women underwent clitoridectomy, a primitive practice that has been discouraged all over the world, though, still practiced by some people in the community and few other tribes in Kenya. This was a rite of passage to adulthood. The names suggested that the woman is unfaithful and immature hence not fit for marriage. A woman who did not meet the expectation of a woman as per the Abagusii definition because of her bad or weird behavior was given names such as ebarimo, richambasi, and richara, meaning mad, thug and foolish, respectively. Such a woman was seen as immature and not fit for marriage. A woman who behaved well as per the societal expectations was perceived as mature and was given names such as omosubati or omongina, meaning a faithful well behaved woman or a clever elderly woman full of wisdom worthy being a model to the younger women, respectively. To sum up, it is good to note that a particular behavior attracted a particular name either to imply maturity or immaturity depending on what the society prescribed to.

C) UGLINESS-This is another quality that featured among many respondents. It is the quality that is the opposite of beauty. This is a pejorative term meant to diminish a woman in Gusii patriarchal society. According to the respondents, in this group, there was no plant. Ugliness is perceived as black

\begin{tabular}{cl}
\multicolumn{3}{c}{ Ontological Correspondence } \\
Source Domain & \multicolumn{1}{c}{ Target Domain } \\
Blackness of an animal or object & $\longrightarrow \quad$ Ugliness of a woman
\end{tabular}

A woman lacking the quality of beauty is mocked by being given the metaphorical names of animals or objects and their attributes which are considered negative and, therefore, perceived as ugly. Such a woman is conceptualized as egekondo, a monkey; a small black animal of the family of primates with a long tail, which uses its limbs to climb trees and lives in hot countries. This is in line with the conceptual metaphor, WOMEN ARE ANIMALS (Kovecses, 2006). The respondents observed that this animal is considered ugly. Enyakaruga is cooking pot; large traditional earthenware for cooking ${ }^{6}$ ugali, and enyang'ni is a cooking pot; traditional earthenware pot for cooking vegetables. The two vessels are used for cooking; both of them are black due to soot. The soot is synonymous with ugliness. This is ironical because most Africans are black. So, according to the respondents, a black woman is perceived as ugly by men. Such a woman was mocked in social gatherings by use of the above metaphors because she was disliked by many men and even shunned for marriage as Rouhi (2011), asserts that some of such metaphors provide amusement and shared pleasure in groups hence reinforcing social bonds.

D) PARASITISM AND LAZINESS. This is another quality that was mapped from animals onto women. This is living off somebody without giving any help or being an opportunist. Culturally, women were supposed to be hard working and contribute to the feeding of the family and community; women looked after the homestead, worked in the fields, fed and raised the children as men protected the family by herding cattle and going for wars. A woman who failed in her duties was perceived as lazy hence a parasite to the man and a liability to the community.

$$
\begin{aligned}
& \multicolumn{2}{c}{\text { Ontological Correspondence: }} \\
& \text { Source Domain } \\
& \text { Parasitism and laziness of an animal } \longrightarrow \text { parget Domain } \\
& \longrightarrow \text { parasitism of a woman }
\end{aligned}
$$

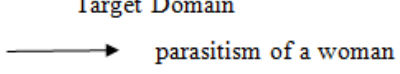

The respondents identified ekenyinyi, leech; a small soft creature that fixes itself to the skin of animals in order to suck their blood. Rigecha or engoa is a kind of arachnid; a very small creature that lives on animals, sucking their blood. Ritusia is a tick; a very small spiderlike insect (arachnid) that bite to fasten themselves onto the skin and feed on sucking blood from the host animal. Ensona is a flea; a very small insect without wings that jumps and bites animals and people to suck their blood. The four are all parasites. The laziness, eating without working and idling of a woman as the man toils to provide for the family is mapped onto the sucking of blood by the parasite (woman) from the host (man). That quality is also mapped onto a woman who loves a man or gets married with an intention of sapping away or stealing his resources (gold digger) like a parasite not giving anything in return to supplement what the man does. According to the respondents, these terms were also meant to discourage laziness and prostitution as such a woman was disliked in the society.

E) HYPOCRISY. This is another negative trait that men

6 Ugali is Gusii (East African) traditional food made out of maize floor cooked like bread eaten with any vegetables and meat or chicken stew. 
assign women to diminish them in a patriachal like Abagusii. Animals which hide as they destroy property are perceived as hypocrites. This value is mapped onto the hypocrisy of a woman.

\begin{tabular}{cl}
\multicolumn{2}{c}{ Ontological Correspondence: } \\
Source Domain & Target Domain \\
Destructive nature of an animal & $\longrightarrow$ \\
Hypocrisy of a woman
\end{tabular}

The respondents identified embongi, weevil; a small insect that feeds on grain, flour etc. and spoils it. Enguko is mole; a small dark furry animal which is almost blind and which usually live under the ground and destroys tubers like sweet potatoes. Risami is pupa; life stage of some simple animals with stinging hair. This animal enters into your clothes stings you and by the time you feel the sting it is gone. All the three are destructive, they hide by the time one realizes, they have destroyed a lot of things. This quality was perceived by the respondents as hypocrisy and therefore, mapped onto the hypocrisy of a woman.

F) IMMORALITY AND SELFISHNESS. These negative traits are mapped from animals perceived as amorous and selfish onto equally amorous and selfish women to mock them. As per the respondents, these traits are highly detested among the Abagusii culture. Some of these metaphors were meant to keep the woman forever subjugated, discourage prostitution and ensure male supremacy.

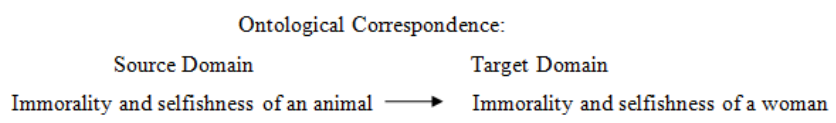

A woman who is immoral and selfish was given names such as, esese (bitch). Kovecses (2006) has a conceptual metaphor, WOMEN ARE PROSITUTES. The Abagusii view dogs as immoral and selfish because of the way they behave during the mating season. They defecate and mate all over making a lot of noise in the open. Other cultures could be conceptualizing a dog as a faithful servant. Engoko is a hen; a common farm bird that is kept for its meat and eggs, fowl. A hen is known for its immorality because it can lie anywhere when it spots a cock. This value is mapped onto a woman who is promiscuous. Such a woman was perceived as dangerous in the community, despised and ridiculed even by fellow women because she could easily snatch other women's husbands and cause embarrassment to the husband.

G) TALKATIVENESS. There is an Ekegusii social cultural code that prohibits a woman from talking too much. The respondents argued that women who talk too much are perceived negatively and despised by men. Thus, they were given names of animals and objects with that quality to mock them.

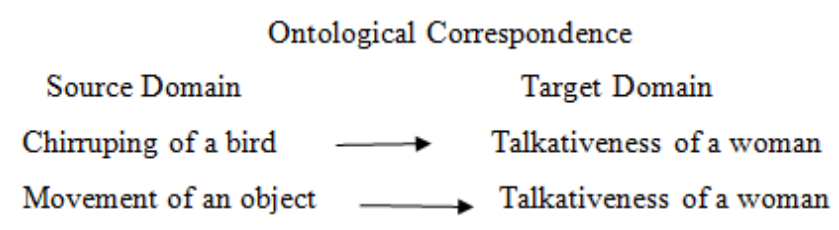

Ekebarabra is a fan or windmill or propeller; an object which rotates very fast. The strong the wind the more it rotates or moves. The rotating nonstop is mapped onto a woman who talks without breaks. Such a woman is viewed by the community as a trouble maker and foolish because it is believed that the bulky of what she speaks is lies, therefore, despised and hated by people. Engoncho is a parrot; a tropical bird with a curved beak and brightly colored feathers that can be taught to ape human speech. Most cultures associate too much talking to being a parrot. In fact, there is an English linguistic metaphor, "talk like a parrot". Women who talk too much are despised in the society and reprimanded by men. Such women were never trusted because they were foolish and never kept secrets. If not married, she risked not getting a husband which was a taboo according to the Ekegusii cultural totems.

H) HARSHNESS. The fierceness of animals and bitterness of parts of plants were mapped onto women perceived as harsh and no nonsense types. These terms were used for women who protected their families, especially the husband and children from evil and trouble shooters in the community. This quality, according to the respondents, can also be given to men.

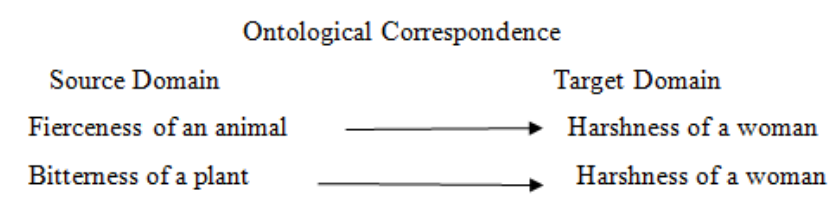

The respondents posited that harshness is another key quality of a woman. This trait mapped from the following animals as the source domain to the woman as the target domain: enchoke and ekiarambe, is a bee and wasp respectively. The two insects are known to be peaceful but when provoked they are very aggressive in fighting back with stings. This quality is mapped onto a woman who is friendly and humble in her territory but loathes the intruders. Bees are hardworking and social insects but the respondents felt that they are overshadowed by fierceness. Some respondents argued that the qualities mapped could depend on the occasion and attitude of the speaker towards a particular woman. Similarly, such a woman is also referred to as obosaro; a bitter concoction of ash made from different herbs used for treatment of different ailments. The Abagusii believed that to cure any ailment, the medicine must be extremely bitter. This is a harsh but hard working woman treasured by the husband and even neighbors in defending her family aggressively. 


\section{Conclusions}

In this study, we have expounded on the socio-cultural metaphor of a woman in Ekegusii language in Kenya where the source and target domains are socio-culturally determined (Grady, 1999). In the light of the present research, it is true that metaphors are plenty in Ekegusii and form networks by which we conceptualize a woman in concrete terms, that is, WOMEN ARE OBJECTS, WOMEN ARE PLANTS, WOMEN ARE ANIMALS AND WOMEN ARE THEIR BEHAVIOUR, based on qualities such as beauty, ugliness, harshness, talkativeness, wisdom, hypocrisy, age, and unfaithfulness. It was also found out that context, the attitude of a speaker and cultural knowledge play a major role in interpreting and understanding Ekegusii woman metaphors. Consequently, it was found out that being a patriarchal society, a woman attracted more negative metaphors than the positive.

We can also conclude that metaphor spice up communication, stretch imagination, and create an imaginative reality to give an insight into everyday experience (Lakoff and Johnson 1980). Finally, we suggest more studies of social-cultural metaphors in other languages to enable a comparative study to determine how similar or different Ekegusii cognitive linguistics is to other Bantu languages and other languages in general.

\section{Appendix}

Ekebarabara- (Van). A very talkative woman often a liar

Embeche-(Warthog) An ugly woman often a liar

Egekondo-(monkey) Ugly woman often liar

Engoncho-(parrot) A very talkative woman often liar

Amarora- (bitter herbs) harsh woman

Rigecha-(tick). Parasitic woman

Ensobosobo-(gooseberry) A beautiful woman

Engoko-(hen) A loose woman morally

Egetanga-(banana plantain) A very productive woman

Enguko-(mole)Woman who meddles in other peoples affairs

Ensona-(flea) parasitic woman

Enchoke-(bee) Hard working woman

Ensombiro-(ant) Great talker often lying

Ekenyinyi-(leech)Parasitic woman

Risami(catapillar) trouble shooter

Egesukari-( sweet banana) beautiful woman

Embongi- (weevil) trouble shooter

Egesagane-( uncircumcised) child

Engombe-(cow)foolish

Ogasusu-( hare) bright

Ekemoni-(cat) beautiful

Engurue-(Pig) greedy and selish
Ekiarambe-(wasp) Harsh woman

Obosaro-(medicinal bitter ash) Harsh woman

Rigecha-(type of arachnid) Parasitic woman

Enyangeni-( vegetable cooking pot) ugly woman

Ensoti-(Vulture) Selfish woman

Ekebunga baiseke-( sweet smelling plant) pretty woman

Ekegwankwa-(butterfly) pretty woman

Ensuri-(bedbug) parasitic woman

Risakwe- (maize stalk) lazy woman

Omoneke (weak tree) lazy woman

Omongina-(behavior) a wise and well behaved woman

Omosubati-(behavior) respectable lady

Richambasi-(behavior) thug

Ebarimo-(behavior) mad woman

Richara-(behavior) foolish woman

Omwana-(behavior) immature woman

Egesagane-(behavior) immature woman

Enyanya-(tomato) beautiful woman

Enyakoruga-(cooking pot) ugly woman

Esese-(dog) loose woman morally

Nyaigoti chenge( type of hen) beautiful woman

Ekerecha-( Evil spirit)hypocrite

Endo-(Lion) harshness 


\section{REFERENCES}

[1] Azuma, M. 2012. "English Native Speakers' Interpretation of Culture-Bound Japanese Figurative Language". In MacArthur $\mathrm{F}$, et al. (eds). Metaphor in Use: Context, Culture and Communication. Amsterdam/Philadelphia: John Benjamin's Vol. 38 pgs 50-80.

[2] Bosire, F. 1993. "Dialects Rogoro and Maate" University of Nairobi Unpublished MA Thesis.

[3] Burke K. 1945. A grammar of motives. Berkeley: University of California Press.

[4] Chomsky, N. 1972. Language and Mind. Enlarged ed. New York, MIT: Harcourt Brace Jovanovich, Inc.

[5] Coulson, S. 2007. Electrifying results: ERP data and cognitive linguistics. In M. Gonzalez-Marquez, I. Mittelberg, S. Coulson \& M. J. Spivey (eds.) Methods in Cognitive Linguistics. Amsterdam: John Benjamins, 400-423.

[6] Dancygier, B. \&Sweetser, E. 2014. Figurative Language. Cambridge: CUP.

[7] Evans. V. \& Green. M. 2006. Cognitive Linguistics. An Introduction. Edinburgh: University Press.

[8] Gibbs, R. W. 1994. The Poetics of Mind. Cambridge: Cambridge University Press..

[9] Gibbs, R. W. 2007. "Why cognitive linguists should care more about empirical methods". In M. Gonzalez-Marquez, I. Mittelberg, S. Coulson \& M. J. Spivey (eds.) Methods in Cognitive Linguistics. Amsterdam: John Benjamin's, 2-18.

[10] Gleason, H. S. Jr.1961. An Introduction to Descriptive Linguistics. New Delhi: Oxford and IBH Publishing Company.

[11] Grady J. 1999 "A typology of motivation for conceptual metaphor: correlation vs. resemblance," in R.Gibbs and G. Steen (eds.). Metaphor in Cognitive Linguistics, John Benjamins, pp. 79-100.

[12] Grady J. 1997. "Theories are buildings revisited," Cognitive Linguistics, 8-4, pp. 267-290.

[13] Hines, C. 1994.'Let Me Call You Sweetheart": The Woman as a Dessert. In Mary Bucholtz A. C. Liang, Laurel A. Sutton\& Catlin Hines (eds) Cultural performances Proceedings of the Third Berkeley Women and Language Conference. Berkeley. CA: Berkeley Women and Language Camp, pp. 295-303

[14] Hiraga, M. 1993. "Shoohin tositeno josee: metafaa ni mirareru joseekan." (Women as goods: views on women seen in metaphors), Nihongogaku, 5-12, pp. 213-233.

[15] Guthrie, M. 1964. The classification of Bantu Languages. London: Dawnson's Pall Mall Publishers

[16] .Kövecses, Z. 1990. Emotion Concepts. Berlin and New York: Springer-Verlag. Metaphor and Culture 219

[17] Kövecses, Z. 2000a. Metaphor and Emotion. New York and Cambridge: Cambridge University Press.

[18] Kövecses, Z. 2000b. American English. An Introduction. Peterborough, Canada: Broadview Press.
[19] Kövecses, Z. 2002/2010. Metaphor. A Practical Introduction. (2010. Second, revised edition). New York: Oxford University Press.

[20] Kövecses, Z. 2005. Metaphor in Culture. Universality and Variation. New York: Cambridge University Press.

[21] Kövecses, Z. 2006. Language, Mind, and Culture. A Practical Introduction. New York: Oxford University Press. Kövecses, Zoltán. In press/2010. A new look at metaphorical creativity. Cognitive Linguistics.

[22] Lakoff, G. 1987. Women, Fire, and Dangerous Things. Chicago: The University of Chicago Press.

[23] Lakoff, G. 1990. The invariance hypothesis: Is abstract reason based on image schemas? Cognitive Linguistics 1: 39-74.

[24] Lakoff, George. 1993. The contemporary theory of metaphor. In Ortony, A. (ed.), Metaphor and Thought, 202-251. Cambridge: Cambridge University Press.

[25] Lakoff, George and Mark Johnson. 1980. Metaphors We Live By. Chicago: The University of Chicago Press.

[26] Lakoff, George and Mark Johnson. 1999. Philosophy in the Flesh. New York: Basic Books.

[27] Lakoff, George and Mark Turner. 1989. More Than Cool Reason. A Field Guide to Poetic Metaphor. Chicago: University of Chicago Press.

[28] Lakoff, George and Zoltán Kövecses. 1987. The cognitive model of anger inherent in American English. In Holland, D. and N. Quinn (eds.), Cultural models in language and thought, 195-221. New York and Cambridge: Cambridge University Press.

[29] Langacker, R. 1999. Grammar and Conceptualization. Berlin-New York: Mouton de Gruyter.

[30] Lyons, R. J. 1968. Introduction to Theoretical Linguistics. New York: Cambridge University Press.

[31] Maalej, Z. 2004. Figurative language in anger expressions in Tunisian Arabic: An extended view of embodiment. Metaphor and Symbol (19), Pp. 51-75

[32] Mac Cormac, E. R. 1985. A Cognitive Theory of Metaphor. Cambridge, Mass: The MIT Press.

[33] Moran, R. 1997. "Metaphor". In B. Hale \& C. Wright (eds.) A Companion to the Philosophy of Language. Blackwell, pp 48-268.

[34] Mugenda, O. \& Mugenda, A. (1999). Research Methodology: Quantitative and Qualitative Approaches. Nairobi: Acts Press.

[35] Nyakoe, G. et al.2012."Conceptualization of Death is a Journey" and Death as a Rest in Ekegusii Euphemism "In Theory and Practice in Language studies: Academy Publishers Vol.2 (7) pp.1452-1457

[36] Rosch, E. 1977. "Human Categorization". In N. Warren (ed.) Advances in Cross-Cultural Psychology 7. London: Academic Press, pp 1-72

[37] Ritchie, D. 2013. Metaphor. New York: Cambridge University Press. 
[38] Rossi, P. 2001. Logic and the art of memory: The quest for a universal language. Translated and with an introduction by Stephen Clucas. London: Athlone Press.

[39] Rouhi M. 2011. Animal Metaphor in Cognitive Linguistics. Iran: David Publishing House.
[40] Takada M. et al. 2006. "A Study of Metaphorical Mapping Involving Socio-Cultural Values: How Woman is Conceptualized in Japanese". In Husby G, Sletton K. \& Michelson (eds) Scandinavian Journal of Immunology: Scandinavia. Vol (8) 394-404

[41] The Kisii Tribe. Retrieved from http://www.kenya-information-guide.com/kisii-tribe.html

[42] Thomas N. (1994. "Detachable Women: Gender and Kinship in Process of Socio-economic Change among the Gusii of Kenya." American Ethnologist 21, pp 516-538. 